remtare and mare mocens attending its performance than belong to most of the operations which I have paseed in roviow.

In concluding this lecture, let me impress upon you the fact, that puncture of the bladder is rarely required if the case has been properly treated. I do not say never-I say mely. The rules which I laid down at the commencement of the lecture are safe, and must be your guide, under circumstances of doubt and difficulty. I wish you to bear in mind also, the chief object I have in view in this lecture, is to show jou the relation of different modes of operating to different forms and complications of urethral obstruction, and to give you some anatomical details which are always safe and sure guides in practice.

Birmingham, March 1855.

\section{ON THE EPIDEMIC OF CARBUNCLES AND BOILS.}

By. THOMAS HUNT, F.R.C.S., Surgen to the Western Dispensary for Diseases of the Skin.

[Read at the Medical Society of London, Saturday, March $10 t h, 1855$.

THE object of this paper is not to propound any new doctrine, but simply to contribute and elicit information, and to promote discussion on the history, pathology, and treatment of an extraordinary epidemic which has long been in existence among us, still exists, and still advances, and of which little but its existence appears to be known at present by the profession. This epidemic consists simply of an extraordinary prevalence of carbuncles, boils, whitlows, pustules, and small superficial collections of purulent matter in various forms. Of these, boils or furuncles have been the most common; hence the disease has been called the furrenculoid epidemic.

I shall endearour as concisely as possible to trace the history and geographic extent of the epidemic, and then say a very few words on its pathology and treatment.

My own attention was first arrested to the prevalence of these diseases in the autumn of $18 \pm 7$, when, at a healthy spot on the coast, at which I had scarcely met with a case of carbuncle once in a year, a remarkable number of cases occurred in rapid succession, extending over the summer of 1848. During the season, I came in contact with several medical visitors from the neighbourhood not only of London, but of various other parts of England, to each of whom I put the question whether a similar frequency of these diseases had been observed. Every practitioner, I think, without exception, replied in the affirmative. Although this might be only a contingency, I could not resist the conclusion that an epidemic existed. Further inquiries satisfied me that the epidemic had extended throughout the whole of England, Wales, Scotland, and Ireland; and I was ultimately enabled to trace it, by evidence which time does not allow me to rehearse, to almost every civilised country on the face of the earth. I have evidence of its existence, almost from that time to the present, in every part of the metropolis and its suburbs, in Oxford, Cambridge, Bath, Bristol, Birmingham, Manchester, and other cities and towns of England and North and South Wales, the northern coast of Kent, the southern coast of Hampshire and the Isle of Wight, in Ireland and in Scotland, in France and Austria, in both the East and West Indies, in the cities of Philadelphia, Boston, and New York, and even at the Cape of Good Hope: and what is most singular, it appears to have broken out almost simultaneously in the four quarters of the globe; in fact, to have originated in some unknown but ubiquitous and universal cause.

It is difficult to ascertain with any approach to accuracy the definite extent of an epidemic which numbers among those attacked a very small proportion of fatal cases. Carbuncle is the only form, indeed, in which the visitation has been at all frequently fatal; and perhaps the best mode of tring the statiotics of the epidemic is to compare the number of fatal asees of carbunclo in diffencent jears: and this we have no means of discovering excopt by reference to the metropolitan districts. Most fortunately, within the last fortnight, an authentic document has been issued by the Registrar-General, which throws light on this question; I refer to A Summary of the Births, Deaths, and Caumes of Deaths, in London, for the fifteen years 1840 to 1854 , compiled from the weekly returns, and published by authority of the Registrar-General. One single sentence in this summary gives a most comprehensive vien of the progress of this epidemic. "Carbuncle", says Mr. Farr, "began to prevail in 1847; and, although it is rarely fatal, the deaths from it in a year have increased from 5 or 6 to 50,70 , and this year (1854) 91." Now, although a considerable deduction is to be made on the score of the increase of the population, yet some extraordinary cause must exist for so remarkable an increase as from 5 or 6 cases in the year to 91. If we further examine the returns, we shall find that the deaths from "phlegmon" and "disease of skin" have increased in a very similar ratio. The diseases comprehended under these heads probably for the most part consisting of some other forms of the same epidemic. It is evident that, up to the end of 1854 , the epidemic was advancing in a geometrical ratio. During the months of January and February in the present year, the deaths from carbuncle appear to have been rather fewer than the previous average; and I should be glad to be informed whether, during the prevalence of the late extremely cold weather, these diseases have been found in the experience of the Fellows, as they certainly have been in mine, less frequent than before the frost.

This very scanty account of the history of the epidemic, I trust. will suffice, because many notices of its existence are to be found in both the British and foreign periodicals, and I do not wish to occupy the time of the Society by dwelling tediously upon what is already familiarly known to all who hear me.

Pathology of the Epidemic. I use this term in its widest sense as comprehending all that is known of the characters and etiology of the epidemic. I have no microscopical observations to offer, nor is it likely, if I had, that they would throw any light on the disease. Neither am I prepared to offer anything relating to the cause of the epidemic, which, like that of other epidemics, is involved in mystery. Sometimes, however, in the absence of positive knowledge, analogy will serve to lend a feeble light where all is darkness beside; and by first marking what is peculiar about this epidemic, and then inquiring whether this peculiarity has recently prevailed in reference to other diseases, we may gain at least a point of comparison which may aid in any future attempts to generalise.

The leading character of the epidemic is, a tendency to the formation and discharge of purulent matter; this tendenoy being confined to the surface of the body. That there exists this superficial localisation as a true character of the epidemic may be proved, not only by general observation, but by $a$ reference to the Registrar-General's returns, from which it appears that while the deaths from "abscess" (a term usually applied to lumbar and other deep-seated collections of matter) - while these appear to have diminished in number during the existence of the epidemic; the deaths from "phlegmon" appear to have more than trebled their usual number during the last few years-this term being employed to denote superficial inflammation generally terminating in suppuration. From Philadelphia and other places, accounts have reached us of the great prevalence of "superficial abscesses and whitlows"; cutaneous eruptions of the vesicular class have been observed speedily to become purulent, especially under depleting treatment, and what is most singular of all, small-pox, a pustular disease frequently terminating in boils and superficial abscesses as sequelæ of the disease, has prevailed with an unusual degrec of severity during the prevalence of the furunculoid epidemic, actually advancing with its advance, and retiring with its mitigation; and, contrary to its usual habits, speedily recurring as an 
crenie and this on the reablishment of the carbuncenhiv tendency. Buch facts as theee would not have escaped the obeervation of our great Sydenham, and at the risk of being thought fanciful, I mas be permitted to point out the evidence of these curious coincidences.

During the four years, $1840,1841,1842,1843$, there was an annual average of deaths from carbuncle of about 3 or 4 only, and an annual average of deaths from small-pox of 771 , including even the epidemic of 1840 . In the following four years, terminating in 1847 , the annual deaths from carbuncle amounted to 8, or double the average, those from smallpox to 981. In the last quarter of 1851 , the deaths from carbuncle increased to the annual ratio of 36 , or nine times the general arerage, those from small-pox also increased to the annual ratio of 1356 . In the first quarter of 1852 , we find the annual ratio for carbuncle 68 , or seventeen times the arerage, that for small-pox 1556 . In the second quarter, the ratio of carbuncle was 32, of small-pox 1888. At this period, both epidemics began rapidly to decline. The her sorer soon increased, until in 1853 they amounted to 70 , whereas the deaths from small-pox, which appeared to have destroyed ncarly all who were susceptible of its fatal influence, fell to 217 . In the year 1854, the deaths from carbuncle rose to 91 , and small-pox again assumed its epidemic form, and is now destroying patients at the rate of 1612 per annum. In no previous year has small-pox had so fearful an epidemic run, after so short a lull, and this in spite of vaccination and its compulsory enactments. Now, although the spread of small-pox from week to week must depena upon contagion and accident, Jet the epidemics of this disease have been so well marked that few can doubt the existence of some unknown cause of its virulence at special periods. This same unknown cause certainly appears to have exerted its influence simultaneously with the diffusion of the tendency to furunculoid disease. What this remote cause consists in does not clearly appear. Equally obscure are the predisposing causes of boils and carbuncles. Formerly it was thought that carbuncles were the result of that peculiar debility or cachexy which is the penalty of luxurious living; but at present it attacks chiefly the class who are necessarily innocent of luxuries, while the upper classes are to a great extent exempt. No age or station is, however, wholly exempt from the influence of the epidemic. It rages at all seasons and in all places and in all weathers. It attacks the healthy and robust indiscriminately with the sickly and weak. The medical profession, often exempted as by a special providence from more fatal epidemics, appear to have been singled out as the special victims of this; yet the disease shews no signs of contagion. Its duration in the person attacked is utterly undefined and undetermined. It may last from a few days to as many months, and may even relapse again and again for years. It neither exempts from the attacks of other diseases nor necessarily accompanies them. The sane and insane, the gouty dyspeptic, and the tuberculous invalid, the young child and the pregnant female all seem alike unprotected and insecure from its attacks. Some patients will have a single carbuncle, others several. Some are literally covered with boils and pustules for months together. Some have one whitlow, others several. I have seen seven fingers in one patient and five in another affected in rapid succession with superficial whitlows surrounding the finger nail and threatening its existence; some have an eruption of bullo speedily becoming purulent; in others, the tarsi are affected with styes, or the ears or scalp with pustules; and in some few, a sort of malignant pustule with a black centre surrounded by an erythematous areola, very much resembling a true plague-spot has appeared on some part of the face and terminated fatally. This has been more common in Paris than in Iondon.

Persons who were previously subject to diseases of the shin have certainly been very commonly afllicted with this epidemic. In the Dispensary for Diseases of the Skin twenty-one per cent. of the patients have been more or less afiscted by the epidemic in some one or other of its rarious forms. Two per cent. have been attacked with carbunclea, eight per cent. with boils, nine per cent. with pustules, and two per cent. with onychia or subcutaneous abscesses.

Treatment. Nothing tends to disturb the complacency of routine practice so effectually as new forms or new developments of epidemic disease. Perhaps few practitioners feel quite at liberty to treat these diseases as they would have treated them ten years ago. No one had then ventured to impugn the orthodox practice of opening a carbuncle at an early stage by a free crucial incision, or of freely opening a boil with the lancet; nor am I quite prepared to condemn this practice at present. I would rather prefer to listen to the experience of the Fellows present than lay down any rulc. In fact, I have tried almost every plan, lancing, cauterising, plastering, fomenting, poulticing, and learing the disease to nature, and my cases have all done well. If a carbuncle is lanced, certainly the incision should not be deep, although it may be extensive. The disease is always superficial. In reference to the superficial whitlows, I have a very decided opinion that poultices do harm rather than good, especially if applied very warm. My plan is, from the first, to apply a spirituous lotion very frequently on a linen rag large enough to envelope the finger and the back of the hand. The bladder of fluid may be opened by a small puncture, but I am not sure whether this is necessary or useful.

The constitutional treatment is far more important than the surgical; and this should be directed to the peculiarities of the case rather than with any special view to the epidemic. Brisk cathartics followed by tonics and acidulated drinks and a generous diet, are very generally indicated, and in tedious, chronic cases, the sulphate of iron is often eminently useful. I have certainly seen many cases in which boils hare been forming for many weeks together, yield in one week or two to a preparation of iron. It may be observed, however, that the health of patients is frequently affected both before and after the epidemic in various ways; but generally the circulation is feeble, the spirits and energy fail, the voice becomes weak and husky, giddiness, lassitude, and weariness, and sometimes sleepless nights are among the symptoms mentioned, and nothing is more common than for the patient to say that he does not feel well, but cannot tell what to complain of. These and other symptoms seem to suggest that some animal poison is present in the blood, which requires elimination, and the manncr in which it can best be accomplished may depend a good deal upon the peculiarities of the case.

In reflecting upon the phenomena presented by this strange epidemic, I beg leave to make a few observations on the points in which it appears to agree with other epidemics, and those in which it differs from them.

1. The most obvious point of agrcement is, that like all other epidemics it finds a congenial soil in debilitated states of the system, and also tends to produce debility in all whom it attacks. In common with cholera, it selects its victims first and chicfly among the ill-fed, the intemperate, and the sickly. It therefore occurs chiefly in the dwellings of the poor. The only medical practitioners who are scarcely aware of its existence, having seen but little of it, are those who have no public connexion with hospitals, dispensaries, or workhouses, and whose practice is chiefly confined to the upper classes of society.

2. Although the more numerous subjects are weakly, still it does attack a small proportion of the robust and healthy. This also is true of the cholera and all other epidemics. These are the only two points in which it appears to partake of the peculiar nature of epidemics in general.

But the most remarkable facts in its history are those in which it differs from all other epidemics.

1. It is certainly not contagious. Some other epidemics may not be contagious, but they are all believed to be 80 by large numbers of acute observers; and I have not yot heard of any medical man who ever suspected the furuncu. loid epidemic to be contagious or infectious, or communi. cable from person to person, in any sense whatever. Here, 


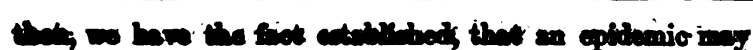

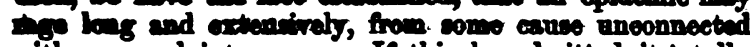
with personel interoourse. If this be admitted, it totally domolishes the negative argument often advanced by contegioniate, that cholers and other epidemics must be comminicable, because otherwise they could not follow the tide of human intercourse.

8. All other epidemics can be traced, for the most part, to some locality where they seem to have originated, and whence they have spread generally westward to other cities, places, and eountries. The furunculoid tendency appears, on the contrary, to have commenced every where at about the same time.

3. Epidemics generally rago only for a time or season, in one and the same place, always quitting it at least for a time, to visit for a short period other places or countries. The epidemic of boils and carbuncles, on the contrary, has existed almost every where for nearly eight years; and, instead of occupying a locality for a limited time, and then declining, it appears, as far as can be collected from reports, to be more or less steadily increasing in severity wherever it has once set its foot.

4. Epidemics are generally so fatal as often to decimate a neighbourhood in a short time; they spread terror wherever they go; and proverbially excite more alarm in the great body of the population than the result proves to have been well founded. But the epidemic under discussion is rarely fatal; it has not made the slightest difference in the average amount of deaths; and, so far from exciting unnecessary alarm, it had raged four or five years, in all parts of the world; before the great bulk of the population were aware of its existence.

In conclusion, I beg to direct attention to a phenomenon connected with the general character of disease at the present time, as having been noticed not very long before the first appearance of the epidemic. For the last ten years or more, our lancets have been rusting in our pockets; we bleed, deplete, and starve our patients, much more reluctantly and cautiously than was the practice twenty or thirty years ago. Most of us have become great conservators of human blood and strength: we dread debility more than destructive inflammation; we prefer to risk the evils of congestion and excessive momentum of blood, to depriving the patient of any portion of that vital fluid which experience has taught us he can ill spare. Why is this? Have the principles of medicine so entirely changed? I doubt it very much. For my own part, I bleed as freely and purge as perseveringly, when I find a fitting subject for depletion, as ever I did in my younger days; but, like my brethren, I am much more cautious, for I feel certain that the type of disease has changed. There is a less vigorous pulse of life, a want of tone and strength and physical endurance, which I rarely met with formerly; and I believe this is the experience of most of my brethren. Now, is it surprising that, with this almost universal atonic, asthenic condition of the public health, an epidemic should have appeared the very distinctive character of which is expressive of debility and depression? Every analogy is in favour of the existence of an asthenic origin. I have observed for many years that, if an inflammatory case of lepra or eczema is treated by excessive depletion, the patient will as certainly have a pustular eruption as he will have a feeble palse. When the hydropathic quackery is carried to extremes, and the patient is drenched with water, and denied not only his accustomed stimulants, but his due allowance of nutritious food, he suffers what is called the "crisis", which means an abominable eruption of pustules and boils, always loathsome, and sometimes fatal: and such an eruption never occurs with a full and firm pulse and a vigorous habit of body. Other facts might be brought to identify a superfeial secretion of purulent matter with a condition of the ajatem impaired by want of due nourishment, or other earses of exhaustion, and incompatible with the existence of robust health. Here, then, we identify the cause of the furunculoid epidomic with the cause of the asthenic typo of divesce which hes changed our penetion; and expond our primciples to the unjust apenvions of the quack. Whother this cause be electric, magnetic, terrestrial, or celestial, wo mas find some instruction in tracing its effects: and, after all, this furunculoid tendency may not be, strictly speaking, an epidemic, so much as the sign of a general deterioration of the physical and sanitary condition of the civilized portion of mankind. Such a condition is possibly the natural destiny of every race of beings, either for a temporary or permanent duration; and it may turn out to be, in the present state of the world, a necessary consequence of the progress of the human race, for the last few centuries, in intellectual refinement-the result of excessive mental labour without needful repose, and of a too earnest straining of the faculties without natural and necessary recreation. It is easy to believe that the exhaustion and enervation thus induced might be transmitted directly and collaterally to future generations, and thus in time reduce a healthy and vigorous population to a state of debility and disease. These speculations of course are open to objection; and they are rather intended as suggestive than as satisfactory : meanwhile, I shall be glad to hear from the Fellows of the Society some better explanation of the cause of this enfeebled and prostrate condition of the human constitution.

Alfred Place, Bedford Square.

\section{PERISCOPIC REVIFW.}

EPIDMIOLOGY, HYGHEICS, AND STATISTICS.

REPORT OF THE PRESIDENT AND COUNCIL OF THE EPIDFMIOLOGICAL SOCIETY ON STATE VACCINATION.

The following very able report we place before our readers in extenso. On a future occasion, we may make some remarks upon it.

ON A PROPER STATE PROVISION FOR THE PREVENTION OF SMALIPOX AND THE EXTENSION OF VACCINATION, PRESENTED TO THE

PRESIDRNT OF THE BOARD OF ITEALTH BY THE PRESIDENT AND COUNCTL OF THE EYDEMMTOLOGICAL SOCIETY.

1. The prevention of disease being the great function of the Board of Health, and the diseases preventible by public measures being chiefly of the epidemic and endemic classes, it is to the alleviation or suppression of these that the attention of the Board will naturaliy be first directed.

2. Amongst them, it will be found that small-pox is still one of the most fatal, destroying, on an average, in London alone, nearly 1,000 persons every year, and, in England and Wales, little short of 8,000 ; whilst, in particular years of epidemic aggravation, the mortality is still more formidable. (Vide Report on the State of Small-Pox and Vaccination in England and Wales, etc., p. 33 and p. 40 .)

3. Yet small-pox is the most preventible of diseases, differing from all other epidemic diseases in this remarkable respect, that, while these latter can only be prevented by discovering and remedying the various conditions (as of crowding, want of drainage, filth, and the like) which give rise to, or assist in the dissemination of, the specific poison of each disease, the former may be guarded against and prevented by a direct prophylactic measure. To small-pox, in short, there is an antidote. The same cannot be affirmed, in the present state of our knowledge, of any other epidemic disease.

4. That antidote is Vaccination. In exact proportion as this has been efficiently practised have the extent and severity of small-pox been diminished over the surface of the world. To the neglect of it, or to its inefficient performance, is due the still large existing mortality in this country-a mortality in striking contrast to that which obtains in some other conntries, in which more adequate provision is made for the vaccination of the people. (Vide Report, pp. 0, 10.) While, out of 1,000 deaths from all causes, there are in England and Wales 21 from small-pox, and in some parts of Ireland upwards of 50,in Sweden, Bohemia, and some of the Italian States, there are not more than 2.

5. The Small-pox and Vaccination Committee of the Epidemiological Society, in a Report on the State of Small-Pox and 